\title{
The Discussion about the Characteristics and Influence of Digital Media Art Design
}

\author{
Chong $\operatorname{Lan}^{1, a}$ \\ ${ }^{1}$ Lanzhou Jiaotong University, Gansu City, Lanzhou Province, 730070, China
}

Keywords: Digital Media; Art design; Characteristics; Influence

\begin{abstract}
Digital technology has accelerated the transformation from tradition to modern in society, and the field of art design is inevitably joined, which makes the digital media art design have become a new subject, therefore, it's of great significance that how to understand the characteristic of Digital Media Design and know about the impact on traditional design and develop new Digital Media Design. Based on the author's learning and practical experience, this paper first analyzed the origin of digital media art design, then researched the characteristics of digital media art design, finally discussed the impact of digital media art design on traditional art design.
\end{abstract}

\section{Introduction}

With the rapid development of digital information, traditional single Media Art Design manifestation has not met the requirement of social development, and nowadays, only by combining digital technology with art design, can the digital technology play a more important role in the design of digital media. Through studying the characteristics of digital media design and analyzing the impact of traditional art design, it helps to promote the rapid development of traditional art and design, to integrate into the development of the era of big data.

\section{The Origin of Digital Media Art Design-The Combination of Art and Digital Technology}

The development of science and technology will provide an opportunity for the reform of art design, constantly promote the innovation and progress of the art, provide an inexhaustible motive force for the prosperity of the art. Seeing from the history, it's not difficult to see that geometry and perspective science provide a perspective theory, make the painting more fit human visual demands; the development of pigment chemistry provides a different levels and diversification colour performance space; the in-depth analysis of human anatomy provides theoretical reference for sculpture, sketch and other artistic creations; research and development of optics lays a theoretical foundation for the development of photographic technology, at the same time, it also provides an optical principle reference for the impressionism painters to explore and organize the image. Therefore, the influence of science and technology on art is obvious, and the progress of science and technology has played a positive role in promoting the development of art.

Starting from the 80s of the last century, the CGD computer graphics becomes a new advanced graphic method sparkles in visual arts and media, such as graphic design, display design, architectural design, environmental design, industrial design, film and television and so on, becomes new show in the field of art design, promotes new development of art design. The rise of CGD computer graphics is called as the third image revolution. compared with previous two times image revolution which from silence to sound, from black and white to color, it has a great time significance. Starting from the 90 s of the last century, combining "computer 
technology science" with "art" is active in the field of art, therefore new media art forms new art form, based on the prosperous development of digital technology. New media art involves visual arts, new media, digital networks, games, animation, advertising, human computer interface, virtual animation and other products, and the research area is in the field of modern digital media.

After entering the 21th century, digital imaging technology, network technology, CG special effects, new media and other creative industries created by digital technology creation have become the core industry of the knowledge economy industry. At present, digital industry is gradually entering a deeper, more extensive development field. Our country is also vigorously developing modern digital industry, it is full of hope.

\section{The Characteristics of Digital Media Art Design}

High efficiency and interactivity. The rapid development of computer software and hardware provides a lot of convenience for designers. The feature of digital technology is easy to make, easy to spread, and the speed of painting has been a magical change, and each idea can be presented on the computer screen immediately. The function of the infinite reproduction and the instantaneous transmission of the network art make the art design expand from the traditional individual creation to the present group replication, and "manufacture" has become an important artistic concept. The carrier of art changes from "work" to "hypertext", "super media". Digitization replaces the traditional elaborate, tedious handicraft, decreases rehandling in the design, reduces the labor intensity of designers, improves the efficiency of design work. So that it can make them focus on more conceptual analysis, creative design, selection and evaluation and other works.

The computer has a huge database, and it becomes designers' materials that can be randomly retrieved. The development of communication technology and computer network technology provide diversity and interactive information for designers, and the designers get a mass of creative inspiration from procedural information. Because of the unique digital image of digital art and the infinite space of artistic creation, the design process is no longer a one-way, but a reversible. The variability of digital design can be arbitrarily changed with the change of design ideas, so it can strengthen the connection with users. Designers achieved a hyperspace, multilevel, multi-field cooperation and exchange, and achieved a rapid communication and feedback, and achieved resources sharing. This kind of interactive art made the design colorful. Because of the emergence of the digital high-speed transformation system, resources sharing becomes a reality.

Virtuality and comprehensiveness. Digital technology provides realistic simulation method, so it can make designers easily and accurately express design intention. Its magical tools can make completed gradient color, lines, strange exaggerated graphics, and the bizarre and motley picture also can be realized by high technology. From plane to three-dimensional, from 2D to 3D, designers can freely gallop in the art space and simulate the real illusion world. In the virtual digital space time, to the traditional media, creating a surreal and high precision design work is difficult to realize, and even to the photography. In virtual reality, the state of the screen is completely replaced by the reality of space, and this realistic virtual reality enriches the designer's artistic inspiration and design element, and expands the space of design thinking, and enables the designer to realize the creativity infinite potential.

The application of digital technology in modern art design promotes the change of aesthetic value system. Designers use the method of traditional artistic expression expertly, at the same time, designers are in the guidance of digital technology, through the combination of text, 
pictures, animation, sound, video and other means, express vividly design intent from all-round, multi angle. So they truly achieve the design effect on map, text, sound, image together. This kind of digital art blurs the boundaries of art and technology, and forms a new art modality that highly integrated science with art, forms new aesthetical trend.

\section{The Influence of Digital Media Art Design on Traditional Art Design}

Design thinking has been extended. Application of digital technology replaces designers to do most part of the rational work, brings a new appearance to the art design of the modeling language, design concept, way of organization, work methods, forms of expression, design efficiency and so on, produces a strong shock, and its far-reaching impact on traditional art and design. Entering the design of the digital information society, and the design object and the psychological environment have changed greatly, and a large number of new products related to modern science and technology has appeared. However, the traditional design product is constantly absorbing the elements of modern information, and makes the product in the product itself and manufacturing with an intelligent color. The design of the product is more humanization, and cold products have the milk of kindness, people is in the environment surrounded by science and technology no longer feel strange, so it becomes a modern design principle. In addition to digital technology allows us to have a convenient and intelligent tools, and extend our design thinking, and design ideas more bold, more extensive design contacts. Opened the field of the designer's inspiration that they could not reach and closed edge for a long-term.

The content of the design has been enriched. The appearance of new transmission forms and media makes the content of visual communication art design enriched and expanded. Network, digital television, interactive media, interactive games, virtual space and so on have become the main form of information dissemination, traditional visual communication design category has suffered breakthrough impact, the development of digital carrier greatly extends visual communication design form and content. The new media art design theory and aesthetic category inherit some theories of traditional visual communication design. The traditional visual communication design theory system can still be used as the theoretical basis of digital media art design. Their theoretical basis is the same. The creative principle in the design of theory and planar vision is similar. the content in the design and performance is similar. Digital media art design is the product of the times, shows the advancement of the times, manifestation is more abundant, the amount of information is larger, more scientific and the times. Therefore, the digital media art design, based on traditional design theory, must according to the way of information transmission, media, and comprehensive discipline of the transmission, the characteristics of digital technology, to improve the new subject.

Means of design has been improved. In the process of traditional art design, designers rely on handwork to draw designs such as the sketch, plan, ceiling plan, elevation, detail drawing and effect drawing. Different people finish design and manufacture. When the product is finished, the designer will discuss the design effect according to the product and static graph. The user and the product are dynamic, a direct interaction process of multiple senses, and the relationship is very different between the designers and the products, rely on user's feedback, and designers know about the design effectiveness that makes the discontinuities in design and use. New media art design makes full use of digital technology. It shows these merits such as easy to store, easy to modify, stable design effect and so on. Eliminating the discontinuities between design and use, make the design finish it in a simulated real situation, improves design effectiveness, to a great extent, eliminate the limitation of the traditional design method, the conception, design, manufacture and use are more coherent and consistent, which makes the product more 
humanization.

\section{Summary}

Digital media art design is a new subject which combines rapid development of digital technology with art, compared with other art subjects, it has the characteristics of practicality, epochal, interdisciplinary and complex. Digital media art design needs new thinking and understanding, if we still keep the original understanding of the concept of art, it will suit neither the development of subject nor the needs of the market. Therefore, it is very important for us to understand and explore correctly the digital media art design and its related fields. With the spread of digital information more deeply and comprehensive, digital media art design will usher in a better development space.

\section{Acknowledgement}

Fund project: The Youth Science Fund Research Project of Lanzhou Jiaotong University(2014060).

\section{References}

[1] Jiang Junjun. Digital media has an influence on environmental art design[J]. Youth Press, 2016, (20): 132-133.

[2] Zhou Ting. Analysis of new media art design that combines art and digital technology[J]. business,

[3] Fan Wenjuan, Yang Zhiwu. Research on the orientation of the subject of digital media art design[J]. Art education research, 2015, (05): 108+110.

[4] Zhaoyong. Digital media environment art design[J]. Popular literature, 2014, (22): 89

[5] Wei Jie.The application of digital media art in exhibition design[J]. art technology, 2013, (09): 90

[6] Pang Xiaoying. New media art design combines art and digital technology[J]. Art science and technology, 2013, (12): 93

[7] Liu Wei. Analysis on the art design in digital media[J]. Science and technology information (Scientific Research), 2007, (20): 333+410. 